\title{
Hubungan Pola Makan, Aktivitas Fisik dan Riwayat Penyakit Keluarga Terhadap Diabetes Melitus Tipe 2
}

\author{
Holy Yunits Nuraini ${ }^{1}$, Rachmat Surpiatna ${ }^{2}$ \\ ${ }^{1,2}$ Program Studi Kesehatan Masyarakat Jenjang S-1 \\ Sekolah Tinggi Ilmu Kesehatan Indonesia Maju \\ JIn. Harapan Nomor 50, Lenteng Agung - Jakarta Selatan 12610 \\ Telp: (021) 78894045, Email: Holyyunita@rocketmail.com
}

\begin{abstract}
Abstrak
Diabetes mellitus tipe 2 adalah diabetes melitus yang tidak tergantung pada insulin dan kebanyakan penderita memiliki kelebihan berat badan. Data studi global menunjukkan bahwa jumlah penderita diabetes melitus pada tahun 201 I telah mencapai 366 juta orang dan diperkirakan akan meningkat menjadi 552 juta pada tahun 2030. Tujuan penelitian ini untuk mengetahui hubungan pola makan, aktivitas fisik dan riwayat penyakit keluarga terhadap penyakit diabetes mellitus tipe 2 di Rumah Sakit Umum Bunda Margonda Depok Tahun 20I5. Penelitian ini bersifat deskriptif dengan desain penelian cross sectional .Metode pengambilan sampel menggunakan tekhnik accidental sampling terhadap 34 orang pasien penyakit dalam di Rumah Sakit Umum Bunda Margonda Depok Tahun 2015. Instrumen penelitian yang digunakan berupa kuisioner, dimana jawaban dari kuisioner dianalisa dengan menggunakan uji chi-square yang di olah dengan menggunakan SPSS. Hasil penelitian menunjukkan bahwa persepsi dari tiga variable yaitu pola makan nilai $p$-value $0.044<\alpha(0.05)$, aktivitas terhadap penyakit diabetes mellitus tipe 2 nilai $p$-value $0.634>\alpha(0.05)$ dan riwayat penyakit keluarga nilai $p$-value $0.102>\alpha(0.05)$, yang mempunyai hubungan terhadap diabetes mellitus tipe 2 adalah variable pola makan. Perlu adanya penyuluhan lebih terhadap masyarakat mengenai pola makan yang baik dan sehat.
\end{abstract}

Kata kunci : Aktivitas Fisik, Diabetes Mellitus, Pola Makan, Riwayat Penyakit Keluarga

\section{Abstract}

Diabetes mellitus type 2 is diabetes mellitus that is independent from insulin and most patients are overweight. Global study data showed the number of people with diabetes in $201 \mathrm{I}$ has reached 366 million and is expected to increase to 552 million in 2030. The purpose of this research is to determine the relationship of dietary habit, physical activity and family medical history diabetes mellitus type 2 at Bunda Margonda General Hospital in 2015. The research is descriptive with a cross-sectional study design. The sampling method using accidental sampling technique to 34 patients of internal disease at Bunda Margonda General Hospital in 2015. The research instrument used in the form of questionnaires, where the answers from the questionnaire were analyzed using chi-square tests were processed using SPSS. The results showed that the perception from three variables are the $p$-value for dietary habit is $0.044<\alpha(0: 05)$, the $p$-value of physical activity diabetes mellitus type 2 is $0.634>\alpha(0,05)$, and the p-value of family medical history is $0.102>\alpha(0.05)$, who are related to diabetes mellitus type 2 is variable of dietary habit. The importance to more counseling to society about dietay habit that is good and healthy.

Keywords : Activity, Diabetes Mellitus, Dietary, Family Medical History 


\section{PENDAHULUAN}

Penyakit Diabetes Melitus atau yang lebih dikenal sebagai penyakit kencing manis adalah kumpulan gejala yang timbul pada seseorang akibat kadar glukosa darah yang tinggi (hiperglikemia). Diabetes Melitus sering kali tidak menyebabkan keluhan yang mengganggu. Namun bila tidak dikelola dengan baik Diabetes Melitus akan menimbulkan komplikasi pada berbagai organ tubuh, seperti pada mata dan ginjal (mikroangiopati), serta pada otak, jantung dan pembuluh darah kaki (makroangiopati). ${ }^{1}$ Pola makanan sehari-hari yang sehat dan seimbang perlu diperhatikan sehingga dapat mempertahankan berat badan ideal. Nutrisi merupakan faktor yag penting pada timbulnya diabetes melitus tipe 2. Gaya hidup yang kebarat-baratan dan hidup santai seta panjangnya harapan hidup merupakan faktor yang meningkatkan prevalensi diabetes melitus. $^{2}$ Diabetes Melitus merupakan masalah kesehatan masyarakat yang nyata dan semakin mencolok. Dari berbagai penelitian epidemiologis di beberapa kota besar di Indonesia jelas didapati peningkatan prevalensi Diabetes Melitus. ${ }^{3}$

Kegemukan dapat memicu terjadinya diabetes melitus. Penelitian pada penduduk menunjukkan bahwa kemungkinan terjadinya diabetes melitus pada orang gemuk lebih besar dari pada orang langsing. Penilaian dilakukan pada penduduk di daerah Depok tahun 2001-2003, adanya kegemukan jelas memperbesar kemungkinan seseorang untuk menjadi diabetes melitus. Pada orang gemuk, karena memakan makan yang berlebihan, sehingga tejadi pengaturan kerja insulin yang tidak normal akibat adanya lemak yang berlebihan pada kondisi badan dengan kegemukan, yang menyebabkan kemampuan sel beta pankreas untuk mengeluarkan insulin akan menurun dan terjadi dibetes melitus. 1 Olah raga secara umum memiliki manfaat meningkatkan stamina, menurunkan berat badan, mengurangi lemak tubuh, mengurangi resiko terkena penyakit degeneratif, memberi rasa bahagia, mengurangi stres, meningkatkan sistem imunitas tubuh dan yang lainnya. Perlunya oleh raga bagi penderita diabetes melitus untuk menurunkan resiko terjadinya TGT ( Toleransi Glukosa Terganggu) dan diabetes melitus tipe $2 .{ }^{4}$

Timbulnya diabetes melitus dipengaruhi oleh faktor keturunan dan perilaku. Faktor keturunan merupakan faktor yang tidak dapat diubah, tetapi faktor lingkungan yang berkaitan dengan gaya hidup seperti kegiatan jasmani yang kurang serta asupan nutrisi yang berlebihan serta kegemukan merupakan faktor yang dapat diperbaiki. Faktor keturunan ini berjalan lambat, sedangkan pandemi diabetes melitus saat ini merupakan cerminan perubahan gaya hidup. ${ }^{2}$ Diabetes melitus tipe 2 didefinisikan sebagai penyakit diabetes yang disebabkan karena sel-sel tubuh tidak menggunakan insulin sebagai sumber energi atau sel-sel tubuh tidak merespon insulin yang dilepaskan pankreas, sehingga dinamakan dengan resistensi insulin. Resistensi insulin tersebut menyebabkan glukosa yang tidak di manfaatkan sel akan tetap berada di dalam darah, semakin lama semakin menumpuk maka pada`saat yang sama terjadi resistensi insulin yang membuat pankreas memproduksi insulin yang berlebihan. Semakin lama, dalam keadaan kondisi yang tidak terkontrol pankreas akan mengurangi jumlah produksi insulin. $^{5}$

Pada awalnya serangan penderita diabetes melitus tipe 2 biasanya mengalami penurunan berat badan, bahkan hingga belasan kilogram. Hal tersebut terjadi karena proses timbunan gula yang gagal diproses menjadi energi sehingga terpaksa menggunakan bantuan lemak tubuh sehubungan dengan keterbatasan insulin yang dimilikinya. Diabetes tipe 2 banyak dipicu 
oleh persoalan gaya hidup yang tidak sehat, sebenarnya dapat dicegah dengan pengaturan pola makan dan olah raga secara teratus. Namun ironisnya jenis penyakit diabetes yang seharusnya dapat dicegah ternyata banyak diderita. Dari semua penderita diabetes melitus, terdapat $90-95 \%$ yang menderita diabetes tipe 2. ${ }^{6}$ Penderita diabetes melitus tipe 2 bisa tidak menunjukkan gejala selama beberapa tahun. Jika kekurangan insulin semakin parah, maka timbulah gejala yang berupa sering kencing dan haus. Jika kadar gula darag sangat tinggi (sampai lebih dari $1000 \mathrm{mg} / \mathrm{dL}$, biasanya terjadi akibat stresmisalnya infeksi atau obat-obatan), maka penderita akan mengalami dehidrasi berat yang bisa menyebabkan kebingungan mental, pusing, kejang dan suatu keadaan yang disebut koma hiperglikemik. ${ }^{7}$ Gejala khas diabetes melitus terdiri dari poliuria, polidipsia, polifagiadan berat badan menurun tanpa sebab yang jelas, sedangkan gejala tidak khas diabetes melitus diantaranya lemas, kesemutan, luka yang sulit sembuh, gatal, mata kabur, disfungsi ereksi pada pria, dan pruritus vulva pada wanita. ${ }^{8}$

Diabetes Melitus merupakan masalah kesehatan masyarakat yang nyata dan semakin mencolok. Dari berbagai penelitian epidemiologis di beberapa kota besar di Indonesia jelas didapati peningkatan prevalensi Diabetes Melitus. Data epidemiologi di Jakarta prevalensi Diabetes Melitus pada penduduk mengalami peningkatan. Pada tahun 1982 di kelurahan Koja Utara Tanjung Priok ditemukan prevalensi Diabetes Melitus sebesar 1,7\% kemudian pada tahun 1991 di kelurahan Kayuputih Jakarta Timur diperoleh angka prevalensi 5,7\% dan pada tahun 2001 di kelurahan Abadi Jaya Depok ditemukan prevalensi Diabetes Melitus sebesar 13,5\%. ${ }^{5}$

Menurut data WHO, Indonesia menempati urutan ke 4 terbesar dalam jumlah penderita diabetes melitus di dunia. Pada tahun 2000 terdapat sekitar 5,6 juta penduduk Indonesia yang mengidap diabetes. Berdasarkan data Global Status Report on NCD yang dirilis Organisasi Kesehatan Dunia (WHO) pada tahun 2010 disebutkan, diabetes melitus menduduki peringkat ke enam sebagai penyebab kematian pada kategori penyakit tidak menular. Rentang usia penderita diabetes bervariasi mulai daro 20 tahun hingga 79 tahun. Studi terbaru di International Diabetes Federation pada 2012 mengungkapkan, penderita diabetes melitus diseluruh dunia mencapai 371 juta orang. Adapun Indonesia masuk dalam urutan tujuh negara dengan penderita diabetes terbanyak. Posisi pertama adalah Cina dengan 92,3 juta penderita, India sebanyak 63 juta jiwa, Amerika Serikat 24,1 juta jiwa, Brasil 13,4 juta jiwa, Rusia 12,7 juta jiwa, Meksiko 10,6 juta jiwa, dan Indonesia dengan jumlah penderita diabetes sebanyak 7,6 juta orang. ${ }^{9}$

Penyakit ini memiliki kaitan erat dengan obesitas. Dari penelitian Palmer terhadap 44.000 wanita di Amerika Serikat menunjukkan bukti bahwa responden yang mengkonsumsi jus atau sari buah dalam kemasan setiap hari memiliki risiko yang lebih tinggi untuk terkena penyakit diabetes tipe 2. Wanita yang meminum dua atau lebih minuman sari buah setiap harinya, risiko untuk terkena diabetes jadi meningkat hingga $31 \%{ }^{6}$

Data studi global menunjukkan bahwa jumlah penderita diabetes melitus pada tahun 2011 telah mencapai 366 juta orang dan diperkirakan akan meningkat menjadi 552 juta pada tahun 2030. Pada tahun 2013, proporsi penduduk Indonesia yang berusia $>$ 15 tahun dengan diabetes melitus adalah 6,9\%. Prevalensi diabetes yang terdiagnosis oleh dokter tertinggi terdapat di DI Yogyakarta (2,6\%), DKI Jakarta (2,5\%), Sulawesi Utara $(2,4 \%)$ dan Kalimantan Timur 
$(2,3 \%)$. Prevalensi diabetes yang terdiagnosis dokter atau berdasarkan gejala, tertinggi terdapat di Sulawesi Tengah (3,7\%), Sulawesi Utara $(3,6 \%)$, Sulawesi Selatan $(3,4 \%)$ dan Nusa Tenggara Timur $(3,3 \%) .^{10}$

Melakukan Diet yaitu menukar makan dengan karbihidrat. Diabetes hendaknya meamkana suber karbohidrat yang kalu dimakan membuat gula darah stabil. ${ }^{11}$ Beberapa penelitian yang mengikutsertakan ribuan responden dan dilakukan dalam jangka waktu tahunan menunjukkan bahwa dengan pengaturan pola hidup yang baik terbukti bahwa pada orang yang berbakat diabetes melitus mungkin terjadinya diabetes melitus dapat dicegah sampai sebesar 50\%. Hasil tersebut bahkan lebuh besar dari pada keberhasilan mencegah terjadinya diabetes melitus yang dilakukan dengan pemberian obat, yang hanya mencapai keberhasilan sebesar $35 \%{ }^{7}$

Data studi global menunjukkan bahwa jumlah penderita diabetes melitus pada tahun 2011 telah mencapai 366 juta orang dan diperkirakan akan meningkat menjadi 552 juta pada tahun 2030. Dengan alasan tersebut peneliti melakukan penelitian dengan judul skrisi "Hubungan Pola Makan, Aktivitas Fisik Dan Riwayat Penyakit Terhadap Penyakit Diabetes Melitus Tipe 2 di Rumah Sakit Umum Bunda Margonda Depok Tahun 2015".

Tujuan penelitian ini adalah mengetahui hubungan pola makan, aktivitas fisik dan riwayat penyakit terhadap penyakit diabetes melitus tipe 2 di Rumah Sakit Umum Bunda Margonda Depok Tahun 2015.

\section{METODE}

Penelitian ini menggunakan pendekatan kuantitatif dengan desain penelitian cross sectional. Data yang diteliti diperoleh dari data sekunder yang diperoleh dari laporan interen rumah sakit serta data primer yang didapatkan dari beberapa pasien yang melakukan kunjungan ke poliklinik penyakit dalam yang mengisi kuisioner, metode penelitian yang digunakan adalah deskriptif.

Penelitian dilakukan pada poliklinik penyakit dalam di Rumah Sakit Umum Bunda Margonda Depok pada tanggal 3 Agustus 2015 sampai tanggal 17 Agustus 2015. Populasi dalam penelitian ini adalah 1299 pasien selama bulan januari sampai bulan juli tahun 2015 yang kontrol pada poliklinik penyakit dalam di Rumah Sakit Bunda Margonda Depok.

Tehnik pengambilan data menggunakan non probability sampling bahwa setiap anggota populasi memiliki peluang nol. Untuk pengambilan sampel, peneliti menggunakan accidental sampling. Dimana metode pegambilan sampel dilakukan dengan memilih siapa yang kebetulan dijumpai atau pengambilan sample didasarkan pada kenyataan bahwa mereka secara kebetulan muncul. Besar sampel yang digunakan dalam penelitian ini berdasarkan rumus untuk desain penelitian cross sectional ditemukan 34 sampel.

Penelitian ini menggunakan data primer yang diperoleh dari kuisioner yang bagikan ke 34 sampel pasien yang berkunjung ke poliklinik penyakit dalam pada 2 minggu pertama pada bulan Agustus 2015.

Dalam menentukan jumlah sampel, peneliti menggunakan data sekunder dari laporan inetern rumah sakit untuk mengetahui jumlah pasien pada bulan Januari-Juli 2015.

Instrumen yang digunakan dalam penelitian ini adalah kuisioner yang berisi pertanyaan mengenai Diabetes Melitu tipe 2 sebanyak 1 pertanyaan, pola makan 20 pertanyaan, aktivitas fisik 11 pertanyaan dan riwayat penyakit keluaraga 1 pertanyaan. Sebelum kuisioner digunakan ke 34 sampel, perlu dilakukan uji validitas dan realibilitas untuk mengetahui kualitas dari kuisioner 
tersebut serta diperoleh distribusi nilai hasil pengukuran mendekati normal.

Peneliti melakukan penelitian langsung di poliklinik penyakit dalam Rumah Sakit Bunda Margonda Depok pada Bulan Agustus Tahun 2015 dengan membagikan kuisioner terhadap sample yang masuk dalam kriteria inklusi yang ditetapkan oleh peneliti. Hasil dari kuisioner dilakukan pengolahan data (pengumpulan data (collecting), editing, coding, tabulating, entry, penyajian data) dan analisa data. Analisis data dilakukan dengan menggunakan anilisis bivariant, dimana analisis tersebut dilakukan untuk mencari hubungan antara variabel independent dan variabel dependent kemudian dianaisis dengan uji Chi Square. Uji kemaknaan digunakan batas kemaknaan sebesar 5\% (0.05):

1. Nilai $\mathrm{P}$ value $<0.05$, maka $\mathrm{H} 0$ ditolak yang artinya adanya perbedaan yang bermakna (signifikan)

2. Nilai $\mathrm{P}$ value $>0.05$, maka $\mathrm{H} 0$ diterima yang artinya tidak adanya perbedaan yang bermakna (tidak signifikan)

\section{HASIL}

Peneliti melakukan pembagian kuisioner terhadap 34 sampel, dari sampel tersebut ditemukan 5 orang menderita diabetes melitus tipe 2 dan 29 tidak menderita penyakit diabetes melitus. Jumlah pasien yang lebih banyak berkunjung ke poli klinik penyakit dalam di Rumah Sakit Umum Bunda Margonda adalah perempuan dengan jumlah 23 pasien dibandingkan dengan jumlah pasien laki-laki dengan jumlah 11 pasien.
Pengunjung lebih banyak berusia di bawah 30 tahun dari pada usia lebih dari 30 tahun.

Berdasarkan penelitian diperoleh bahwa mayoritas pasien di poli klinik penyakit dalan Rumah Sakit Umum Bunda Margonda Depok tidak menderita diabetes melitus sebesar 29 orang dari 34 sampel dengan persentase $85,3 \%$ dan yang menderita penyakit diabetes melitus tipe 2 berjumlah 5 orang dengan persentase $14,7 \%$.

Pasien di poli klinik penyakit dalam Rumah Sakit Umum Bunda Margonda Depok dengan pola makan baik berjumlah 17 orang dari 34 sampel dengan persentase 50\% dan yang memiliki pola makan buruk berjumlah 17 orang dengan persentase $50 \%$.

Tabel 1. Analisis Univariat

\begin{tabular}{lcc}
\hline Variabel & Frekuensi & Presentase \\
\hline DM Tipe 2 & & \\
Menderita DM & 5 & $14,7 \%$ \\
Tdk Menderita DM & 29 & $85,3 \%$ \\
Pola Makan & & \\
Baik & 17 & $50 \%$ \\
Buruk & 17 & $50 \%$ \\
Aktivitas Fisik & & \\
Baik & 15 & $44,1 \%$ \\
Buruk & 19 & $55,9 \%$ \\
Riw Peny Keluarga & & \\
Ada & 9 & $26,5 \%$ \\
Tdk Ada & 25 & $73,5 \%$ \\
\hline
\end{tabular}

Pasien di poli klinik penyakit dalam Rumah Sakit Umum Bunda Margonda Depok melakukan aktivitas fisik buruk sebesar 19 orang dari 34 sampel dengan persentase $55,9 \%$ dan yang melakukan aktivitas fisik dengan baik berjumlah 15 orang dengan persentase $44,1 \%$.

Tabel 2. Analisis Bivariat

\begin{tabular}{|c|c|c|c|c|c|c|c|c|c|}
\hline \multirow{2}{*}{\multicolumn{2}{|c|}{ Variabel }} & \multicolumn{4}{|c|}{ Hubungan Terhadap DM Tipe 2} & \multirow{2}{*}{\multicolumn{2}{|c|}{ Total }} & \multirow{3}{*}{$\begin{array}{c}\text { P- } \\
\text { Value }\end{array}$} & \multirow{3}{*}{ OR } \\
\hline & & \multicolumn{2}{|r|}{ DM } & \multicolumn{2}{|c|}{ Tidak DM } & & & & \\
\hline & & $\mathbf{N}$ & $\%$ & $\mathbf{N}$ & $\%$ & $\mathbf{N}$ & $\%$ & & \\
\hline \multirow{2}{*}{ Pola Makan } & Buruk & 0 & $0 \%$ & 17 & $100 \%$ & 17 & $100 \%$ & \multirow{2}{*}{0,44} & \\
\hline & Baik & 5 & $29,4 \%$ & 12 & $70,6 \%$ & 17 & $100 \%$ & & \\
\hline \multirow{2}{*}{ Aktivitas Fisik } & Buruk & 2 & $10,5 \%$ & 17 & $89,5 \%$ & 19 & $100 \%$ & \multirow{2}{*}{0,634} & 0,471 \\
\hline & Baik & 3 & $20 \%$ & 12 & $80 \%$ & 15 & $100 \%$ & & $0,068-3,261$ \\
\hline \multirow{2}{*}{$\begin{array}{l}\text { Riw Penyakit } \\
\text { Keluarga }\end{array}$} & Ada & 3 & $33,3 \%$ & 6 & $66,7 \%$ & 9 & $100 \%$ & \multirow{2}{*}{0,102} & 5,750 \\
\hline & Tdk Ada & 2 & $8 \%$ & 23 & $92 \%$ & 25 & $100 \%$ & & $0,78-42,58$ \\
\hline
\end{tabular}


Dari table diatas dapat dilihat bahwa dari 34 pasien yang teliti, yang melakukan pola makan yang buruk dan menderita diabetes melitus yaitu tidak ada, yang melakukan pola makan yang buruk dan tidak menderita diabetes melitus yaitu sebesar 17 pasien. Untuk yang melakukan pola makan dengan baik dan menderita diabetes melitus berjumlah 5 pasien dan yang melakukan pola makan dengan baik tetapi dan tidak menderita diabetes melitus sebesar 12 pasien. Dari hasil uji statistic dengan menggunakan alat bantu SPSS, diperoleh nilai $\mathrm{p}$-value pada variabel pola makan $0,044<\alpha(0,05)$, sehingga dapat dinyatakan bahwa ada hubungan antara pola makan diabetes melitus tipe 2 .

Pasien yang melakukan aktivitas fisik yang buruk dan menderitas penyakit diabetes melitus yaitu 2 pasien, dan yang melakukan aktivitas fisik yang buruk dan tidak menderita penyakit diabetes melitus yaitu sebesar 17 pasien. Sedangkan pasien yang melakukan aktivitas fisik dengan baik dan menderita penyakit diabetes mleitus ditemukan 3 pasien dan yang melakukan aktivitas fisik yang baik tetapi tidak menderita penyakit diabetes melitus sebesar 12 pasien. Dari hasil uji statistic dengan menggunakan alat bantu SPSS, diperoleh nilai $\mathrm{p}$-value pada variabel aktivitas fisik $0,634>\alpha(0,05)$, sehingga dapat dinyatakan bahwa tidak ada hubungan antara aktivitas fisik diabetes melitus tipe 2 .

Pasien yang memiliki penyakit keluarga dengan diabetes melitus dan menderitas penyakit diabetes melitus yaitu 3 pasien, dan yang memiliki penyakit keluarga dan tidak menderita penyakit diabetes melitus yaitu 6 pasien. Sedangkan pasien yang tidak memiliki penyakit keluarga dan menderita penyakit diabetes melitus ditemukan 2 pasien dan yang tidak memiliki penyakit keluarga tetapi tidak menderita penyakit diabetes melitus sebesar 23 pasien. Dari hasil uji statistic dengan menggunakan alat bantu SPSS, diperoleh nilai p-value pada variabel riwayat penyakit keluarga $0,102>\alpha(0,05)$, sehingga dapat dinyatakan bahwa tidak ada hubungan antara riwayat penyakit diabetes melitus tipe 2 .

\section{PEMBAHASAN}

\section{Keterbatasan Penelitian}

Penelitian ini menggunakan rancangan penelitian cross sectional, dimana variabel dependent dan independent diamati dalam waktu yang bersamaan. Penelitian ini hanya melihat hubungan antara variabel dependent dan independent, kemudian diperoleh tingkat kemaknaan hubungan antara variabel yang dibahas sebagai hasil penelitian. Hasil penelitian ini tidak menggambarkan adanya hubungan sebab akibat.

Proses pengumpulan data penelitian (penyebaran kuisioner pada 34 sampel) dilaksanakan terhadap pasien yang berkunjung ke poliklinik penyakit dalam Rumah Sakit Umum Bunda Margonda Depok dimulai pada pukul 08.00-14.00 pada tanggal 03 Agustus sampai tanggal 17 Agustus 2015. Dalam melakukan penelitian ini, peneliti dibantu oleh salah satu perawat yang bertugas di poliklinik penyakit dalam untuk mengawasi pasien dalam pengisian kuisioner. Kurang bersedianya pasien dalam mengisi kuisioner menjadi hambatan peneliti dalam mencukupi jumlah sample yang dibutuhkan, sehingga membutuhkan waktu lebih lama untuk mencukupi jumlah sampel.

\section{Hubungan Pola Makan Terhadap Diabetes Melitus Tipe 2}

Hasil penelitian yang telah dilakukan di Rumah Sakit Umum Bunda Margonda Depok Tahun 2015 mengenai hubungan pola makan terhadap diabetes melitus tipe 2, dari 34 sampel yang diteliti yang memiliki pola makan buruk dan menderita diabetes melitus adalah $0(0 \%)$, pola makan buruk tanpa diabetes melitus adalah 17 (100\%), pola makan baik dengan diabetes melitus adalah 5 $(29,4 \%)$ dan pola makan baik tanpa diabetes melitus adalah $12(70,6 \%)$. Setelah dilakukan pengolahan data dengan menggunakan program SPSS diperoleh p-value 0,044 dimana nilai $p$ lebih kecil dari nilai $\alpha(0,05)$. Hasil penelitian menunjukkan terdapat hubungan antara pola makan terhadap penyakit diabetes melitus tipe 2 , terlihat pada nilai $\mathrm{p}$-value yang diperoleh dari perhitungan statistik. 
Tidak diragukan bahwa nutrisi merupakan factor yang penting dalam timbulnya diabetes melitus tipe 2 . Gaya hidup yang kebarat-baratandan hidup santai merupakan factor yang meningkatkan prevalensi diabetes melitus. Pola makan sehari-hari yang sehat dan seimbang perlu diperhatikan, sehingga dapat mempertahankan berat badan ideal. himbauan gizi seimbang untuk membantu mencegah berbagai penyakit termaksud mencegah berbagai penyakit termaksud mencegah atau memperlambat tercetusnya diabetes melitus. ${ }^{2}$

Berdasarkan penelitian yang telah dilakukan oleh Sartika Sumangkut, Wenny Supit dan Franly Onibala mengenai hubungan pola makan terhadap kejadian penyakit diabetes melitus tipe 2 diperoleh p-value 0,000 , dimana nilai $\mathrm{p}$ ini lebih kecil dari nilai $\alpha(0,05)$. Kesimpulan dari penelitian bahwa ada hubungan antara pola makan terhadap kejadian diabetes melitus tipe $2 .^{12}$

Sebuah penelitian yang dipublikasikan pada The Nurses Health Study ditemukan bukti bahwa mereka yang megkonsumsi setidaknya satu jenis minuman manis bersoda setiap hari akan memiliki risiko terkena diabetes tipe 2 yang dua kali lebih besar dibandingkan dengan mereka yang jarang mengkonsumsinya. Peneliti di Rutgers percaya bahwa tingginya tingkat konsumsi terhadap fruktosa memiliki hubungan yang mendukung bagi terjadinya perkembangan diabetes tipe 2. Tidak diragukan bahwa nutrisi merupakan faktor yang penting dalam timbulnya diabetes melitus tipe 2 . Gaya hidup yang kebarat-baratandan hidup santai merupakan factor yang meningkatkan prevalensi diabetes melitus. Pola makan sehari-hari yang sehat dan seimbang perlu diperhatikan, sehingga dapat mempertahankan berat badan ideal. Himbauan gizi seimbang untuk membantu mencegah berbagai penyakit termaksud mencegah berbagai penyakit termaksud mencegah atau memperlambat tercetusnya diabetes melitus. ${ }^{8}$

Makanan porsi kecil dalam waktu tertentu akan membantu mengontrol kadar gula darah, sedangkan makanan dalam porsi besar menyebabkan peningkatan glukosa darah secara mendadak dan bila berulangulang dalam jangka panjang keadaan ini dapat menimbulkan komplikasi diabetes melitus. Oleh sebab itu dianjurkan makan sebelum lapar karena makan disaat lapar sering tidak terjadwal dan berlebihan. Agar kadar glukosa darah lebih stabil, perlu pengaturan jadwal makan yang teratur.

Berdasarkan penelitian yang dipublikasikan dalam American Journal of Clinical Nutrition (Juli 2002), Ditunjukkan bukti-bukti bahwa makanan yang memiliki indeks glikemik tinggi akan meningkatkan resiko seseorang untuk terkena diabetes tipe 2. Penelitian tersebut menyarankan agar penderita diabetes melakukan diet indeks glikemik, namun tetap berhati-hati dengan bahan makananyang memiliki kandungan lemak tinggi. ${ }^{8}$

Hasil penelitian sebelumnya selaras dengan hasil penelitian yang dilakukan di Rumah Sakit Bunda Margonda Depok, bahwa ada hubungan antara pola makan terhadap diabetes melitus tipe 2. Pola hidup manusia sangat mempengaruhi kesehatan seseorang, sama seperti pola makan. Jika pola makan tidak dapat dijaga, maka bisa saja penyakit mudah menyerang tubuh kita. Jenis makanan, jumlah makanan serta waktu makan sangat mempengaruhi berat badan ideal.

\section{Hubungan Aktivitas Fisik Terhadap Diabetes Melitus Tipe 2 di Rumah Sakit Umum Bunda Margonda Depok Tahun 2015}

Hasil penelitian yang telah dilakukan di Rumah Sakit Umum Bunda Margonda Depok mengenai hubungan aktivitas fisik terhadap diabetes melitus tipe 2, dari 34 sampel ditemukan yang melakukan aktivitas fisik buruk dengan diabetes melitus adalah 2 $(10,5 \%)$, aktivitas fisik buruk tanpa diabetes melitus adalah 17 (89,5\%), aktivitas fisik baik dengan diabetes melitus adalah 3 (20\%) dan aktivitas fisik baik tanpa diabetes melitus adalah 12 (80\%). Setelah dilakukan pengolahan data diperoleh p-value 0,634 dimana nilai $\mathrm{p}$ lebih besar dari nilai $\alpha(0,05)$, sehingga dapat dinyatakan bahwa tidak ada 
hubungan antara aktivitas fisik terhadap diabetes melitus tipe 2 .

Olah raga akan membantu membakar kalori. Semakin banyak kalori yang terbakar, semakin banyak pula kadar gula yang tersera tubuh. Berdasarkan data pada Magnetic Resonance Imaging atau scam MRI, seorang yang berjalan kaki selama 10 menit setiap hari lemaknya akan terbakar 20\%. Ini akan meningkatkan kemampuan otot dalam menyimpan gula. Penelitian yang dilakukan oleh Michael Goran dari University of California menunjukkan gejala adanya kolerasi antara olahraga dengan penyakit diabetes tipe 2 . Olah raga ternyata mampu menurunkan resistensi insulin secara signifikan. ${ }^{8}$

Beberapa penelitian yang mengikut sertakan ribuan responden dan dilakukan dalam jangka waktu tahunan menunjukkan bahwa dengan pengaturan pola hidup yang baik dengan melakukan aktivitas fisik terbukti bahwa pada orang yang memiliki bibit diabetes melitus kemungkinan terjadi diabetes melitus dapat dicegah sampai sebesar $50 \%$. Hasil tersebut bahkan lebih besar daripada keberhasilan mencegah diabetes melitus yang dilakukan dengan pemberian obat yang hanya mencapai keberhasilan sebesar 35\%. ${ }^{1}$

Berdasarkan penelitian yang telah dilakukan oleh Agus Sudaryanto, Noor Alis Setiyadi dan Diah Ayu Frankilawat, mengenai hubungan antara pola makan, genetik dan kebiasaan olah raga terhadap kejadian penyakit diabetes melitus tipe 2 diperoleh p-value 0,002 pada kebiasaan olah raga (aktivitas fisik), dimana nilai $\mathrm{p}$ ini lebih kecil dari nilai $\alpha(0,05)$. Kesimpulan dari penelitian bahwa ada hubungan antara aktivitas fisik terhadap kejadian diabetes melitus tipe $2 .^{14}$

Hasil penelitian sebelumnya tidak selaras terhadap penelitian yang dilakukan di Rumah Sakit Umum Bunda Margonda Depok, dimana penelitian sebelumnya menyatakan ada hubungan antara aktivitas fisik terhadap diabetes meltus dan hasil dari peneliti menyatakan tidak ada hubungan antara aktivitas fisik terhadap diabetes. Aktivitas fisik pada umumnya sangat bermanfaat bagi setiap orang yang melakukannya, karena dapat meningkatkan kebugaran, mencegah kelebihan berat badan, meningkatkan funfsi jantung, paru-paru, otot serta memperlambat penuaan. Untuk Diabetes melitus sendiri, aktivitas fisik berfungsi dalam pencegahan terjadinya penyakit tersebut, dimana dengan menjalankan aktivitas fisik secara teratur dan berkesinambungan dapat menjaga berat badan ideal.

\section{Hubungan Riwayat Penyakit Keluarga Terhadap Diabetes Melitus Tipe 2}

Hasil penelitian yang telah dilakukan di Rumah Sakit Umum Bunda Margonda Depok mengenai hubungan riwayat keluarga terhadap diabetes melitus tipe 2, dari 34 sampel yang diteliti ditemukan yang memiliki riwayat penyakit keluarga dan menderita diabetes melitus adalah 3 (33,3\%), ada riwayat keluarga tanpa menderita diabetes melitus adalah $6(66,7 \%)$, tidak ada riwayat penyakit keluarga dan menderita diabetes melitus adalah $2(8 \%)$ dan tidak memiliki riwayat keluarga diabetes melitus tanpa menderita diabetes melitus adalah 23 (92\%). Setelah dilakukan pengolahan data diperoleh p-value 0,102 dimana nilai $p$ lebih besar dari nilai $\alpha(0,05)$, sehingga dapat dinyatakan bahwa tidak ada hubungan antara riwayat penyakit keluarga terhadap diabetes melitus tipe 2.

Berdasarkan penelitian yang telah dilakukan oleh Agus Sudaryanto, Noor Alis Setiyadi dan Diah Ayu Frankilawati, mengenai hubungan antara pola makan, genetik dan kebiasaan olah raga terhadap kejadian penyakit diabetes melitus tipe 2 diperoleh p-value 0,000 pada riwayat penyakit keluarga, dimana nilai $\mathrm{p}$ ini lebih kecil dari nilai $\alpha(0,05)$. Kesimpulan dari penelitian bahwa ada hubungan antara aktivitas fisik terhadap kejadian diabetes melitus tipe $2 .^{14}$

Faktor keturunan merupakan faktor yang tidak dapat diubah karena faktor keturunan adalah faktor yang berpengaruh dalam terjadinya diabetes melitus, tetapi faktor lingkungan yang berkaitan dengan gaya hidup seperti kegiatan jasmani yang kurang 
dan asupan nutrisi yang berlebih serta kegemukan merupakan faktor yang dapat diperbaiki. $^{2}$

Seseorang yang kedua orang tuanya menyandang diabetes melitus akan lebih mungkin menderita diabetes melitus daripada seseorang dimana kedua orangtuanya tidak menderita diabetes melitus. Demikian juga bila salah satu dari orang tua ada yang menderita diabetes melitus, tidak menutup kemungkinan salah seorang anaknya ada yang menderita diabetes melitus. Walaupun demikian, bukan berarti jika kedua orang tua tidak menyandang diabetes melitus maka ia tidak akan menderita penyakit tersebut. Factor lingkungan banyak berpengaruh pada terjadinya diabetes melitus. Hidup santai, tidak pernah melakukan kegiatan jasmani, kegemukan dan makan yang berlebihan, semuanya dapat mempercepat terjadinya dieabetes melitus. ${ }^{15}$

Hasil penelitian sebelumnya tidak selaras terhadap penelitian yang dilakukan di Rumah Sakit Umum Bunda Margonda Depok, dimana penelitian sebelumnya menyatakan ada hubungan antara riwayat penyakit keluarga terhadap diabetes melitus tipe 2 dan hasil dari peneliti menyatakan tidak ada hubungan antara riwayat penyakit keluarga terhadap diabetes melitus tipe 2 . Riwayat penyakit keluarga tanpa disadari telah melekat ditubuh seseorang jika salah satu anggota keluarga ada yang memiliki penyakit diabetes melitus. Namun, penyakit diabetes melitus tersebut tidak akan muncul jika orang yang memiliki bibit penyakit tersebut dapat mengatur pola hidup sehat dengan baik. Perlunya menjaga pola hidup sehat baik pola makan dan melakukan aktivitas fisik dikarenakan untuk menjaga tubuh tetap dalam kondisi sehat.

\section{KESIMPULAN}

Dari tiga variabel yang dilakukan penelitian, di Rumah Sakit Umum Bunda Margonda Depok Tahun 2015, ditemukan bahwa pola makan sangat berpengaruh terhadap timbulnya penyakit diabetes melitus tipe 2, dimana diperoleh nilai p-value $0.044<$ $\alpha$ (0.05). Maka perlu adanya pengontrolan terhadap jenis makanan, porsi atau jumlah makan dan selalu memperhatikan indeks glikemik pada makanan yang dimakan.

\section{SARAN}

Bagi pihak rumah sakit perlu memberikan info atau penyuluhan lebih kepada pasien maupun masyarakat sekitar mengenai pola makan yang baik dan sehat berdasarkan jenis makanan, porsi makan dan waktu makan.

\section{DAFTAR PUSTAKA}

1. Waspanji Sarwono. Hidup Sehat Dengan Diabetes "Diabetes Melitus: Apakah Itu?". Jakarta; 2007..

2. Sukardji Kartini. Hidup Sehat Dengan Diabetes "Gizi Sehat dan Seimbang Mencegah Diabetes Melitus". Jakarta; 2007..

3. Soewando, Pradana. Hidup Sehat Dengan Diabetes "Upaya Pencegahan Diabetes Melitus". Jakarta; 2007.

4. Ilyas, Ermita. Hidup Sehat Dengan Diabetes "Mencegah Diabetes Melitus dengan Olahraga". Jakarta; 2007.

5. Helmawati T. Hidup Sehat Tanpa Diabetes. Jakarta; 2014..

6. Soewando Pradana. Hidup Sehat Dengan Diabetes "Penjaringan Penyandang Diabetes Melitus". Jakarta; 2007..

7. Purnamasari D. Diagnosis dan klasifikasi diabetes melitus. In A. W. Sudoyo, B. Setiyohadi, I. Alwi, M. S. K \& S. Setiati (Eds.), Buku ajar ilmu penyakit dalam jilid III edisi v. Jakarta; 2009.

8. Sigit Yulianto. Makanan Berbahaya Untuk Diabetes. Jakarta; 2014..

9. Dewanti Sri. Buku Pintar Kesehatan Kolestrol, Diabetes Melitus dan Asam Urat. Jawa Tengah; 2010..

10. Kemenkes. Riset Kesehatan Dasar : Riskesda. 2013. Jakarta; 2013..

11. L Phaidon. Diabetes. Jakarta Selatan; 2012

12. Sumangkut S, Supit W dan Onibala F. Hubungan Pola Makan dengan Kejadian Penyakit Diabetes Melitus Tipe 2 Di Poli Interna Blu RSUP Prof. Dr. R. P Kandou Manado. [Jurnal]. Manado; 2014.

13. Ilyas Ermita. Hidup Sehat Dengan Diabetes "Latihan Jasmani Bagi Penyandang Diabaetes Melitus". Jakarta; 2007.

14. Sudaryanto A, Alis N dan Ayu D. Hubungan Antara Pola Makan, Genetik Dan Kebiasaan Olahraga Terhadap Kejadian Diabetes Melitus 
Tipe 2 Di Wilayah Kerja uskesmas Nusukan

Banjarsari. [Jurnal]. Semarang; 2014.

15. Waspadji S. Pertanyaan Pasien Dan

Jawabannya Tentang Diabetes. Jakarta; 2007. 